\title{
A STUDY ON CLINICAL ASSESSMENT OF VARICOSE VEINS BY CLINICAL SCORES AND VALIDATING THE OUTCOME OF TRENDELENBURG PROCEDURE IN VARICOSE VEINS OF LOWER LIMBS
}

\author{
Nilavi Ratnam¹, Alagarsamy Ramaiah ${ }^{2}$ \\ ${ }^{1}$ Chief Civil Surgeon, Department of General Surgery, Government Medical College and ESIC Hospital, Coimbatore. \\ ${ }^{2}$ Senior Resident, Department of General Surgery, Government Medical College and ESIC Hospital, Coimbatore.
}

\begin{tabular}{l}
\hline ABSTRACT \\
\hline BACKGROUND \\
Varicose veins of the lower limbs is a common clinical condition. ${ }^{1}$ that we encounter in the surgical clinics of our hospital-the \\
ESIC Hospital. The term varicose is derived from the Latin word "varix" meaning bent and refers to dilated, tortuous and \\
lengthened veins of lower limbs. ${ }^{2}$
\end{tabular}

\section{AIM}

This was aimed to study on clinical assessment of varicose veins by clinical scores and validating the result of Trendelenburg procedure in varicose veins of Lower Limbs. This study was conducted in the Department of General Surgery, ESIC Hospital, over a period of 12 months.

\section{METHODS AND MATERIALS}

This analytical study group consisted of 92 patients between 20 to 80 yrs., inclusive of both males ( $\mathrm{n}=78$ ) and females ( $\mathrm{n}=14$ ). They were assessed for severity of varicose veins by documenting a detailed history, clinical examination findings, imaging studies on a pre-structured case sheet and the result of surgery. It was found that majority of the patients were $\leq 60 \mathrm{yrs}$. and the left lower limb was predominantly affected in both sexes.

\section{RESULTS}

Using the VCSS system, 19.57\% ( $n=18)$ cases had mild disease, $67.39 \%(n=62)$ cases had moderate disease and $13.04 \%(n=12)$ had severe disease. In the present study as per the VDS system, majority of the patients (n=51) $55.43 \%$ had grade III disability and $40.22 \%(n=37)$ of the patients had moderate grade of venous reflux, i.e. venous reflux duration $<1$ second. All 92 patients had surgery with majority had uneventful postoperative periods $58.17 \%(n=52)$, whereas a few had complications $44.44 \%(n=40)$.

\section{CONCLUSION}

A statistically significant result was found for the clinical assessment scores and also for the surgical outcome.

\section{KEYWORDS}

VCSS, VDS, VRS, Venous Reflux, Trendelenburg Procedure, Varicose Veins.

HOW TO CITE THIS ARTICLE: Ratnam NMS, Ramaiah AMS. A study on clinical assessment of varicose veins by clinical scores and validating the outcome of Trendelenburg procedure in varicose veins of lower limbs. J. Evolution Med. Dent. Sci. 2016;5(50):31873190, DOI: $10.14260 /$ jemds/2016/739

\section{INTRODUCTION}

Varicose veins of the lower limbs is a common clinical condition. ${ }^{1}$ that we encounter in the surgical clinics of our hospital-the ESIC Medical College and Hospital. The term varicose is derived from the Latin word "varix" meaning bent and refers to dilated, tortuous and lengthened veins of lower limbs. ${ }^{2}$ Varicose veins of lower limb occur due to loss of valvular efficiency, which is a product of the resultant venous hypertension in standing position. Most commonly occurs in females compared to males according to western studies. In contrast to western studies, males are more affected than females in our hospital as per statistics (male=258, female=82).

Financial or Other, Competing Interest: None.

Submission 23-05-2016, Peer Review 05-06-2016,

Acceptance 07-06-2016, Published 21-06-2016.

Corresponding Author:

Dr. Nilavi Ratnam,

No. 9, Kurinji Nagar,

Goldwins, Coimbatore.

E-mail: drnilavi@yahoo.com

DOI: $10.14260 /$ jemds/2016/739

\begin{abstract}
AIM OF THE STUDY
This was aimed to Study on Clinical Assessment of varicose veins by clinical scores and validating the result of Trendelenburg procedure in varicose veins of Lower Limbs.
\end{abstract}

\section{MATERIALS AND METHODS}

After consulting with the statistician, the sample size set was 92 patients in the study. Both Venous Clinical Severity Score [VCSS] and Venous Disability Score [VDS] were evaluated by Questionnaire and Clinical Examination. The non-invasive standard colour Doppler examination was performed for assessing the following parameters: i) Grading of venous reflux at SFJ. ii) Competency of SPJ. iii) Patency and competency of deep venous system of lower limb. In this study conducted at ESIC Medical College and Hospital, Coimbatore, for the period of 12 months. After obtaining informed consent, a total of 92 patients with primary varicose veins from those who were admitted for surgery in wards were included. The history was taken recording symptoms, duration of disease and occupation. The degree of disability was assessed by questionnaire. The site of varicose veins, system involved (LSV or SSV or Perforator incompetence) 
and if any associated complications were assessed by clinical examination. Abdominal and pelvic examinations were done to rule out abdominal tumours and other causes of raised intra-abdominal pressure. Cardiovascular system and peripheral arterial pulses were carefully examined to exclude arterial disease associated with varicose vein. The patients underwent standard colour Doppler ultrasonogram to find out system of involvement [LSV or SSV]. In patients with LSV involvement, further grading of venous reflux at saphenofemoral junction was assessed. By using colour Doppler, sapheno-popliteal junction and deep venous system were assessed for reflux and thrombosis respectively after history and clinical examination and colour Doppler examination, patients were categorized into three groups. The three groups were divided as mild, moderate and severe according to the scores 0-9, 10-20, 21-30 respectively. After categorization correlation was done by Pearson method. The venous reflux is of three types. They are grade I, grade II, grade III according to the duration elicited by venous Doppler examination. Normally venous reflux is absent at SFJ. Presence of reflux is considered as abnormal. The duration of reflux was measured and graded as follows: The Grade I-upto 0.5 second, Grade II-0.5 to 1 second, Grade III-more than 1 second. Clinically all 92 patients were classified as mild, moderate and severe category according to Venous Clinical Severity Score (VCSS) to correlate with VRS. a) Mild (0-9), b) Moderate (10-20), c) Severe (21-30) with the Venous reflux score (Grade1/2/3). Further all the patients were classified according to Venous Disability Score (VDS) into mild, moderate and severe category for correlation with VRS. a) Mild (1), b) Moderate (2), c) Severe (3) with the venous reflux score (Grade 1/2/3). All the 92 patients underwent surgery by the following methods such as Trendelenburg method, i.e. flush ligation of sapheno-femoral junction, subfascial ligation of perforators, segmental excision of varicosities, saphenopopliteal ligation and split skin graft according to the clinical severity.

\section{RESULTS AND DISCUSSION}

This study was designed to assess the validity of the surgical procedures and clinical scores in management of varicose veins of lower limbs. Ninety two patients between 20 to 80 yrs. were recruited in this study, which was conducted over a period of 12 months.

\section{Age}

In our study majority of patients belong to 41 to 50 years' age group were affected (43\%) $(n=40)$ (Table 1.1).

\begin{tabular}{|c|c|c|c|}
\hline $\begin{array}{l}\text { Sl. } \\
\text { No. }\end{array}$ & $\begin{array}{l}\text { Age Group } \\
\text { (In Years) }\end{array}$ & $\begin{array}{c}\text { No. of } \\
\text { Patients }\end{array}$ & Percentage \\
\hline 1 & $20-30$ & 8 & 9 \\
\hline 2 & $31-40$ & 25 & 27 \\
\hline 3 & $41-50$ & 40 & 43 \\
\hline 4 & $51-60$ & 17 & 18 \\
\hline 5 & Above 60 & 2 & 2 \\
\hline \multicolumn{2}{|r|}{ Total } & 92 & 100 \\
\hline
\end{tabular}

\section{Sex}

Among the 92 patients studied, of which 78 (85\%) were males and 14 (15\%) were females (Table 1.2).

\begin{tabular}{|c|c|c|c|}
\hline Sl. No. & Sex & No. of Patients & Percentage \\
\hline 1 & Male & 78 & 85 \\
\hline 2 & Female & 14 & 15 \\
\hline \multicolumn{2}{|c|}{ Total } & 92 & 100 \\
\hline & Table & ex Wise Classif & \\
\hline
\end{tabular}

\section{Duration of Illness (Pre-Operative)}

During preoperative assessment we found that majority of the patients, i.e. 58 out of $92(63 \%)$ suffered by varicose veins between 5 and 15 years, whereas few had the diseases between 15 and 20 years (Table 1.3).

\begin{tabular}{|c|c|c|c|}
\hline $\begin{array}{c}\text { Sl. } \\
\text { No. }\end{array}$ & $\begin{array}{c}\text { Duration of Illness } \\
\text { (In Years) }\end{array}$ & $\begin{array}{c}\text { No. of } \\
\text { Patients }\end{array}$ & Percentage \\
\hline 1 & $<5$ & 19 & 21 \\
\hline 2 & $5-10$ & 28 & 30 \\
\hline 3 & $10-15$ & 30 & 33 \\
\hline 4 & $15-20$ & 15 & 16 \\
\hline \multicolumn{3}{|c|}{ Table 1.3: Duration of Illness (Preoperative) } \\
\hline
\end{tabular}

\section{Duration of Hospital Stay}

The following table depicts the duration of hospital stay with different manifestations (Table 1.4).

\begin{tabular}{|c|c|c|c|}
\hline Sl. No. & $\begin{array}{c}\text { Duration of Hospital } \\
\text { Stay (In Days) }\end{array}$ & $\begin{array}{c}\text { No. of } \\
\text { Patients }\end{array}$ & Percentage \\
\hline 1 & $5-10$ & 58 & 63 \\
\hline 2 & $10-15$ & 32 & 35 \\
\hline 3 & $15-20$ & 2 & 2 \\
\hline & Total & 92 & 100 \\
\hline \multicolumn{4}{|c|}{ Table 1.4: Duration of Hospital Stay } \\
\hline
\end{tabular}

\section{Side of Varicose Vein in Lower Limbs}

In our study, 44 were affected on left side of lower limb, whereas 43 were affected on right side of the lower limb and 5 had varicose vein in both limbs (Table 1.5).

\begin{tabular}{|c|c|c|c|}
\hline $\begin{array}{c}\text { Sl. } \\
\text { No. }\end{array}$ & $\begin{array}{c}\text { Side of Lower } \\
\text { Limbs }\end{array}$ & $\begin{array}{c}\text { No. of } \\
\text { Patients }\end{array}$ & Percentage \\
\hline 1 & Right & 43 & 47 \\
\hline 2 & Left & 44 & 48 \\
\hline 3 & B/L & 5 & 5 \\
\hline \multicolumn{3}{|c|}{ Table 1.5: Side of Varicose Vein in Lower Limbs } \\
\hline
\end{tabular}

\begin{tabular}{|c|c|c|}
\hline VCSS & No. of Patients & Percentage \\
\hline Mild & 18 & 19.57 \\
\hline Moderate & 62 & 67.39 \\
\hline Severe & 12 & 13.04 \\
\hline Total & $\mathbf{9 2}$ & $\mathbf{1 0 0 . 0 0}$ \\
\hline \multicolumn{2}{|c|}{ Table 1.6: Clinical Score (VCSS) } \\
\hline
\end{tabular}

The following tables show the result of clinical and imaging scores (Table 1.7, 1.8, 1.9).

\begin{tabular}{|c|c|c|}
\hline VDS & No. of Patients & Percentage \\
\hline 0 & 10 & 10.87 \\
\hline 1 & 22 & 23.91 \\
\hline 2 & 52 & 56.52 \\
\hline 3 & 8 & 8.70 \\
\hline Total & $\mathbf{9 2}$ & $\mathbf{1 0 0 . 0 0}$ \\
\hline \multicolumn{3}{|c|}{ Table 1.7: Clinical Score (VDS) } \\
\hline
\end{tabular}




\begin{tabular}{|c|c|c|}
\hline VRS & No. of Patients & Percentage \\
\hline Mild & 4 & 4.35 \\
\hline Moderate & 37 & 40.22 \\
\hline Severe & 51 & 55.43 \\
\hline Total & $\mathbf{9 2}$ & $\mathbf{1 0 0 . 0 0}$ \\
\hline \multicolumn{2}{|c|}{ Table 1.8: Imaging Score (VRS) } \\
\hline
\end{tabular}

\section{Venous Doppler Study Findings}

In our study, out of 92 patients 76 had saphenofemoral reflux and 16 had saphenopopliteal reflux (Table 1.9).

\begin{tabular}{|c|c|}
\hline $\begin{array}{c}\text { Doppler Study Findings } \\
\text { in Lower Limbs }\end{array}$ & No. of Patients \\
\hline Saphenofemoral Reflux & 76 \\
\hline Saphenopopliteal Reflux & 16 \\
\hline Perforator Incompetence & 90 \\
\hline <3 Perforator Incompetence & 40 \\
\hline 3-5 Perforator Incompetence & 24 \\
\hline 5-8 Perforator Incompetence & 21 \\
\hline 8-12 Perforator Incompetence & 5 \\
\hline \multicolumn{2}{|c|}{ Table 1.9: Findings in Venous Doppler Study } \\
\hline
\end{tabular}

\section{Surgical Management}

All 92 patients had different methods of surgical procedure in accordance with their clinical severity of the varicose veins in lower limbs (Table 1.10).

\begin{tabular}{|c|c|c|}
\hline $\begin{array}{c}\text { Sl. } \\
\text { No. }\end{array}$ & Types of Surgical Procedure & $\begin{array}{c}\text { No. of } \\
\text { Patients }\end{array}$ \\
\hline 1 & Saphenofemoral Ligation Only & 2 \\
\hline 2 & $\begin{array}{c}\text { Saphenofemoral Ligation with } \\
\text { Subfascial Perforators Ligation }\end{array}$ & 45 \\
\hline 3 & $\begin{array}{c}\text { Saphenofemoral Ligation, } \\
\text { Saphenopopliteal and Perforators } \\
\text { Ligation }\end{array}$ & 16 \\
\hline 4 & $\begin{array}{c}\text { Perforators Ligation only } \\
\text { Ligation with Segmental excision of } \\
\text { varicosities }\end{array}$ & 15 \\
\hline 6 & \multicolumn{2}{|c|}{ Along with SSG for ulcers } \\
\hline \multicolumn{2}{|c|}{ Table 1.10: Surgical Management } \\
\hline
\end{tabular}

\section{Post-operative Complications}

All 92 patients had surgery with majority had uneventful postoperative periods $58.17 \%(\mathrm{n}=52)$, whereas a few had complications $44.44 \%(n=40)$ (Table 1.11).

\begin{tabular}{|c|c|c|}
\hline Sl. No. & Complications & No. of Patients \\
\hline 1 & Haematoma & 2 \\
\hline 2 & Wound gapping & 4 \\
\hline 3 & Wound sinus & 10 \\
\hline 4 & Recurrent ulcers & 10 \\
\hline 5 & Oedema leg & 14 \\
\hline 6 & Uneventful post-op periods & 56 \\
\hline \multicolumn{3}{|c|}{ Table 1.11: Post-Operative Complications } \\
\hline
\end{tabular}

Among the 92 patients, $78(85.0 \%)$ were males and 14 $(15.0 \%)$ females. In both the sexes, left lower limb was found to be predominantly affected. On analysing the Venous Clinical Severity Score (VCSS) of the 92 patients, a minimum pain score of 1 was seen in $46.74 \%$ of the cases under study and a maximum of 3 in $18.48 \% ; 19.57$ percent of the cases had a varicosity score of 1 and $13.04 \%$ had a score of 3 . There was no oedema in $23.91 \%$ of the cases, whereas a maximum score of 4 was seen in $4.35 \%$. Twenty two percent of the cases had no skin changes, whereas $4.35 \%$ cases had a maximum score of 4 . Forty six percent of the patients did not have any ulcers and $10.87 \%$ of them had a maximum score of 4. On categorizing our patients as per the VCSS system, we found that $19.57 \%(n=18)$ fell into mild and $67.39 \%(n=62)$ into moderate category, whereas $13.04 \%(n=12)$ came under the severe group. Hence, as per VCSS $67.39 \%$ cases had moderate disease. On analysing the Venous Disability Score (VDS) of the 92 patients, it was found that majority of them had Grade II disability ( $n=52)$ (56.52\%), only $8.70 \%(n=8)$ of them had Grade III disability and $23.91 \%(n=22)$ had Grade I VDS. Hence, as per VDS system $56.52 \%(n=52)$ of the patients had Grade II disability. On analysing the venous reflux score grades among the 92 patients, a significant proportion of them $(n=51,55.43 \%)$ had Grade 3 reflux and Grade 1 and 2 reflux was seen in only $4.35 \%(n=4)$ and $40.22 \%(n=37)$, respectively. Hence, in our study $55.43 \%(n=51)$ patients had Severe grade of Venous Reflux (VRS). We found that majority had undergone the SFJ Flush ligation and multiple perforator ligation $50.0 \%(n=45)$. We also analysed the post-operative outcome, which revealed majority had uneventful periods $58.17 \%(n=56)$. There was no correlation between VDS and VRS (Pearson correlation coefficient $=0.129$, $P$ value $=0.268$ ) . We also found that the clinical features assessed as per VCSS correlated well with the disability caused by varicose veins in lower limbs, assessed using the VDS. This observation was statistically significant (Pearson correlation coefficient $=0.266$, P value- 0.021 ). Edinburgh vein study from Scotland by Vascular Surgery Department in 2002 by Pearson et $\mathrm{al}^{3}$ and Rachel et $\mathrm{al}^{4}$ showed a strong correlation between lower limb clinical features and venous reflux by Doppler ultrasound scanning. ( $n=466$ patients, $p$ value: 0.012 ) Vasquez. $^{5}$ et al done a study to assess the quality of life changes in varicose vein treatment in 499 patients by venous clinical severity score and found to be useful ( $p$ value; 0.002 ) to measure the changes in the varicose vein treatment. Bradberg 6 et al and Munschauer CF. ${ }^{7}$ et al studied to identify the usefulness of VCSS system in varicose vein risk assessment and to evaluate the changes after varicose vein treatment in 68 patients. The study concluded that VCSS was useful ( $p$ value: 0.015 ) in the above measurement. In 2006 Gilet. $^{8}$ et al done a study include 2894 patients to compare the parameters between VCSS and CEAP in varicose vein management and concluded that the VCSS was a very good system ( $p$ value: 0.001 ) in diagnosis and followup of chronic venous insufficiency of lower limbs. Padberg. ${ }^{9}$ et al and Bradbury AW.10 et al in 2000 done a study in 191 patients to find out which one was better in varicose vein clinical features assessment and measure the changes after treatment for varicose vein among CEAP and VCSS and found VCSS would be the ideal tool ( $p$ value: 0.001 ) to measure the outcome and risk assessment in varicose vein compared to CEAP, which already existed for many years. Jones. ${ }^{11}$ and Fischer. ${ }^{12}$ et al found that the surgery was reasonable definitive therapy of primary varices, but secondary varices usually require rest, elevation and elastic support. 


\section{CONCLUSION}

Ninety two cases of varicose veins of the lower limb have been studied in a prospective manner strictly abiding to the objectives, inclusion and exclusion criteria. An analysis of the data has enabled us to arrive at the following conclusions. 1) Varicose vein develops as a result of venous reflux and the same is responsible for the clinical features and its complications. Intervention in Grade II and III venous reflux in asymptomatic patients can be the ideal treatment to prevent complications. 2) The surgery (Different procedures) is a reasonable definitive therapy of varicose veins, as it prevents disease related morbidity, 3) Present clinical score systems is easily applicable to all patients as a bed side score compared to traditional scoring systems.

\section{REFERENCES}

1. Russell RCG, Williams NS, Christopher JK, et al. Bailey and love's short practice of surgery 24th ed. London: Arnold 2004:p 954.

2. Tjandra JJ, Clunie GJA, Kaye AH, et al. Textbook of surgery $3^{\text {rd }}$ ed. Blackwell publishing 2005:p 501.

3. Persson AV, Jones C. Use of the triplex scanner in diagnosis of deep venous thrombosis. Arch Surg 1989;124(5):593-6.

4. Rachel CS, Andrew WB, Veins V, et al. Vascular and endovascular surgery 3rd ed. Elsevier Saunders 2006:p 373-89.

5. Vasquez MA, Wang J, Mahathanaruk M, et al. The utility of the venous clinical severity score in 682 limbs treated by radiofrequency saphenous vein ablation. J Vasc Surg 2007;45(5):1008-14.
6. Bradbury A, Evans CJ, Allan P, et al. The relationship between lower limb symptoms and superficial and deep venous reflux on duplex ultrasonography: the Edinburgh vein study. J Vasc Surgery 2000;32(5):921-31.

7. Vasquez MA, Munschauer CE. Venous clinical severity score and quality-of-life assessment tools: application to vein practice. Phlebology 2008;23(6):259-75.

8. Gillet JL, Perrin MR, Allaert FA. Clinical presentation and venous severity scoring of patients with extended deep axial venous reflux. J Vasc Surg 2006;44(3):588-94.

9. Rutherford RB, Padberg FT, Comerota AJ, et al. Venous severity scoring: an adjunct to venous outcome assessment. J Vasc Surg 2000;31(6):1307-12.

10. Bradbury AW, Stonebridge PA, Ruckley CV, et al. Recurrent varicose veins: correlation between preoperative clinical and hand-held Doppler ultrasonographic examination, and anatomical findings at surgery. Br J Surg 1993;80(7):849-51.

11. Jones L, Braithwaite BD, Selwyn D, et al. Neovascularization is the principal cause of varicose vein recurrence: results of a randomized trial of stripping the long saphenous vein. Eur J Vasc Endovasc Surg 1996;12(4):442-5.

12. Fischer $\mathrm{R}$, Linde $\mathrm{N}$, Duff $\mathrm{C}$, et al. Late recurrent saphenofemoral junction reflux after ligation and stripping of the greater saphenous vein. J Vasc Surg 2001;34(2):236-40. 